periosteum was divided along the course of the rib and reflected with a raspatory and a good inch of rib was removed with bone forceps. A fine trocar and cannula was smployed as a guide to the pus, and the track was opened up by sinus forceps and a large cavity was reached in the lung from which about ten or more ounces of foetid pus and gas escaped. The aperture made by the forceps was further renlarged by passing the finger through about an inch or so of condensed tissue which bled rather profasely at first but the hamorrhage soon ceased. The abscess caviry appeared to be irregular and was lined with much broken-down and softened ,material, but its complete exploration was impossible the inger not being long enough to map out its limits with any precision. A wide rubber drainage-tube about six inches long was introduced, no attempt being made to irrigate the abscess cavity. The wound was dressed with a pad of wood-wool freely covered with iodoform. Morphia (4 grain) combined with atropine ( $\frac{1}{4}$ th grain) was given bypodermically. By the next day the patient had rallied wonderfully well, the temperature had come down to $99^{\circ}$ and the pulse had dropped to 96 . The sputum showed marked decrease and was almost odourless. The dressing was saturated with horribly offensive pus, the edges of the wound were covered with a very adherent dirtygrey material and there was some cellalitis in the immediate neighhourhood. On Jan. $27 \mathrm{th}$ the temperature again rose to $101^{\circ}$ and the pulse reached 114 . There was conGiderable cyanosis with marked laboured breathing and much rambling and the whole body was bathed in perspiration. Tine crepitations ard bronchial breathing were to be heard :over the greater part of the right lung but there was no appreciable increase in the dulness. A mixture of ammonium carbonate, digitalis, nux vomica, and senega was freely given together with considerable quantities of brandy. The patient's condition for the next tew days was very critical but a marked improvement took place on Feb. $3 \mathrm{rd}$. An evening temperature of only $99.2^{\circ}$ was then registered, the circulation had improved, the bronchial breathing had disappeared, and the fine crepitations had given way to moist raes. By this time also she had begun to sleep well, the rambling had ceased, and the sweating had markedly diminished. In addition the wound had cleaned, the discharge had become odcurless and the sputum quite sweet, and the quantity daily expectorated did not amount to more than an ounce. Three days later the temperature being normal the tube was shortened half an inch. On Feb. 13th she was allowed to sit up for a short time. The tongue had quite cleaned and the appetite was good, there was practically no expectoration and as the discharge through the wound was now slight the tube was shortened to three inches. The after history was uneventful. On Feb. 24th the tube having slipped out it was not replaced and on March 7th, six weeks after the operation, the wound closed. She rapidly gained in weight and strength and is now (December) in perfect health. There is not the slightest iign of cough or trace of expectoration. No retraction or bnlging of one side of the chest can be made out, the neasuiement from the spinous process to mid-sternum at the level of the scar boing $15 \mathrm{in}$. on either side; in fact there is now nothing to show except a cicatrix with some deficiency of resonance and weak breath sounds in its neighbourhood.

Remarky.-This case presents several points of interest. wsere is, firstly, its successful issue, a sufficient rarity of italif to be worth recording. Another feature was the discovery of a simple serous pleuritic effusion in the vicinity of the paimonary abscess. Had the aspirating needle hit upon this at the first puncture the correct diagnosis wonld probably nos have been then arrived at and the patient would consequently have lost her life. Again, the rapid obliteration of the large abscess carity and the few physical signs now remaining to indicate the previous serious condition are also toteworthy.

Manchester.

Corporation Homes at. Dartmouth.-At the neeting of the Dartmouth Town Council held on Dec. 10th it wiss stated that $\mathrm{Mi}$. Richard Burford Searle, L.R.C.P. Eord, M.R.C.S. Eng, had offered $£ 2000$ at 3 per centi. intarest to the council for carrying out their scheme of coporation hornes morided a particular site named by him is available and chosen. He also proposes that on his and his wife's death the poperty should revert entirely to the corporation.

\section{CASES OF ACUTE ATAXY OF ONE LIMB.}

BY H. CAMPBELL THOMSON, M.D., M.R.C.P.LOND., MEDICAL RLGISTRAR TO THE MIDULFSEX HOSPITAL.

THE two cases I have recorded below are interesting examples of an acute onset of ataxy in one limb. They appear to be widely different in origin, for while the first was accompanied by definite symptoms of organic disease the second was apparently functional in character and seemed in some way to be connected with over use of the muscles. Ataxy of acute onset limited to one arm or leg is a rare condition, and when resulting from organic disease of the cord is probably in most cases due to a focal lesion situated somewhere in the posterior columns so that the muscular sense impressions are interzapted. Sir William Gowers ${ }^{1}$ mentions a group of cases (to which he has given the name of acute myelitic ataxy) which were characterised by an acute onset of ataxy in one arm accompanied by complete muscular anæsthesia so that all power of estimating weights was lost although the cutaneous sensibility might be perfect. The condition usually reached its height in a few hours, remained complete for some weeks, and then slowly disappeared, and it probably depended upon some organic lesion of an inflam. matory character. In the first case given below, although the ataxy was limited to the left arm the other symptoms were widely distributed over the cord and the right arm was the only limb which was not affected in some way or otber.

CASE 1. -The patient was a man, aged forty-eight years, who was admitted to the Middlesex Hospital on June 4th, 1896, under the care of Dr. Sidney Coupland, to whose kindness I am indebted for permission to publish the notes. There was nothing of importance in the family history and previously to this illness the patient had never been laid up. He was a man of moderate habits and there was no history of specific disease. On May $29 \mathrm{th}$ in the middle of the morning as the patient was walking home he felt giddy and noticed that his left leg seemed heary, and he also found that be was unable to pass his urine. On reaching home he sat down and did not try to walk again for the rest of the day. Towards the evening he felt some numbness in his left band, and control over the movements of that limb was lost so much that if he tried to touch his face with his hand, the movements were so erratic that he hurt himself. On the next day (May 30th) there was some weakness of the right leg; it could be moved but the patient was not able to stand. There was no weakness of the right arm. He was admitted into hospital on June 4th complaining of loss of power in the legs and the left arm. On examination it was found that there was some slight weakness of the left arm accompanied by marked incoördination, so that the patient was quite unable to perform simple movements with any degree of accuracy, and he stated that this symptom had been much worse, and was now less marked than it had been. The power of distinguishing weights was not lost and there was no anæsthesia. There was considerable loss of power in the left leg. The limb was extended and turned on its inner side and although some movements could be performed at the knee- and ankle-joints the leg as a whole could not be raised. The right leg was also weak but much less so than the left and it could be raised off the bed. There also seemed to be some loss of movement of the lower intercostal muscles. There was alteration of sensation over the trunk and lower limbs commencing at a line about one inch below the nipple. If the point of a pin was drawn down the chest the pain ceased to be felt at the level of that line and became changed into a dull sensation of touch. Heat and cold could not be recognised with any certainty below the same level. Sensation to touch was considerably diminished and the loss was more marked in the left than in the right leg. There was no annsthesia of the left arm. There was neither girdle pain nor zone of hyperasthesia. All control over the sphincters was completely lost and the urine had to be drawn off. The abdominal, plantar, and epigastric reflexes were all absent and so also were the knee-jerks and the deep reflexes of the left arm. There were no bedsores. 
On the 5th the symptoms had improved. The line of anæsthesia was a little lower and the movements of the left arm were more coördinated but still very clumsy. On the 8 th the plantar reflex could be obtained on the right side but there was no alteration of the other reflexes. There was also some increase of power in the lower extremities. On the 9 th both plantar reflexes could be obtained and there was also a very slight return of knee-jerk on both sides. on the 16th power over the sphincters had returned. The patient from this time continued to improve very rapidly and when seen some weeks afterwards he was quite well, his gait was normal, he had perfect control over the sphincters, and the knee-jerks were both present.

The symptoms in this case make it quite clear that the ataxy depended on an organic lesion, and its mode of onset points to the nature of the lesion being an inflammatory one and of a disseminated type. It is especially interesting to note that there was no angsthesia of the arm or loss of sensibility to weights but with regard to the latiter symptom it must be stated that it was not tested until after the ataxy had begun to improve so that possibly there may have been some sensory alteration when the disease was at its worst. Another important feature of the case was the very rapid recovery which took place, especially with regard to the ataxic symptoms which passed off in a very few days.

CASE 2. - The second case was that of a woman, aged fiftyeight years, who complained of inability to use the left arm. She stated that she was in her usual health until the evening of Sept. 4th when she noticed a tingling in the left arm and hand and she also thought that her left leg dragged a little. She took very little notice of these symptoms until the next day when she found she had lost control over the movements of the left arm. This annoyed her especially at meals, for she was quite unable to guide a fork to her mouth with the left hard and she was afraid to try much lest she should hurt herself. Shs also found that she dropped things if she held them in the left hand. I saw her first on the 6 th, two days after the onset of the symptoms, and there was then still very marked incoördination of the left arm. On attempting to touch any point the fingers went very wide of the mark, so much so that on trying to put her finger to her mouth she missed her face altogether. There was no anæsthesia either over the arm or elsewhere, weights could be well distinguished, and she could also tell what position the limb was put into. There appeared to be some slight weakness of the limb. No definite symptoms could be found in the left leg either motor or sensory. I did not see her again until a week had passed, and by that time the incoördination had almost entirely passed asay. She still complained of sensations of numbness, tingling, and coldness all down the left side of the body but no anæsthesia or other objective symptoms conld be found. At the end of another week the patient was again seen and the ataxy had then quite disappeared. The coldness of the left side had improved but some tingling and numbness, especially of the left arm, still remained. Otherwise she expressed herself as perfectly well.

With regard to the cause in Case 2 the patient put it down to the fact that she had lately been obliged to carry heavy weights. For three weeks before the attack she had carried a large bucketful of water from the top to the bottom of a house and vice vers $\hat{\alpha}$ and the journey was made altogether about four times a day. She stated that she al ways used the left hand and that she felt a great strain on coming down stairs as she always kept the arm stiff and held the pail well away from the body in order not to spill the water. There were no signs whatever of any organic lesion in this case. On the whole it seemed probable that fatigne was the cause of a temporary functional derangement of the movements of the limb which caused a loss of harmony between the actions of the different muscles and so produced the clumsy morements.

Queen Anne-street, W.

West of EngLand Eye Infirmary, Exeter.The committee of the West of England Eye Infirmary. Ereter, which receives patients from all parts of Devon and Somerset, is anxious to erect a new building on the present site. To carry out their full plans $\$ 30,000$ would be required, but in order to meet present exigencies $\$ 10,000$ is asked for. As has been already stated in THE LANCET an anonymous donor has recently given $£ 2000$ and on Dec. $10 \mathrm{th}$ two anonymous gifts of $£ 1000$ and $£ 105$ respectively were received.

\section{Clinital eqtotes:}

\section{MEDICAL, SURGICAI, OBSTETRICAL, AND THERAPEUTICAL.}

\section{A CASE OF OTITIS MEDIA ACUTA HEMORRHAGICA.}

BY J. T. C. NASH, M.B., C.M. EDIN.

A WOMAN, aged forty-seven years, whose powers had been overtaxed by long and incessant nursing and anxiety, was suddenly seized about 2 o'clock one morning with severe pain in both ears. She stated that the pain was very acute for about an hour when the ears went "pop" and blooc began to stream from them. When I saw the patient, abous 8 A.M., I was shown several pellets of blood-saturated wool while from both ears there still issued a copious seresanguineous discharge. Hearing was markedly deficiention both sides. Each drumhead showed a recent tear. There was a history of some ear trouble when a child but of none in the meanwhile. Under careful treatment the disoharge ceased after passing through serous and purulent stages. There was at no time any odour. In the course of the affection the mastoid cells on both sides became involved but the inflammation quickly resolyed. The patient made a thorough recovery with normal hearing power. The tympana were left only slightly opaque but the tears had healed.

No doubt the early and free hæmorrbage was of benefit. Both ears were simultaneously affected, but the pharynz was not inflamed.

Beckenham.

A NOTF ON A RARE DEFORMITY.

By CyrLl H. Flory, M.R.C.S. Eng., L.R.C.P. LoND.

ON Oct. 3rd last a primipara in the course of a natural labour was delivered of a male infant who is bilaterally "club-handed"-that is to say, the child's hands are situated at the lower end of the ulna but articulate loosely with the inner lateral aspect of the same. Both radii are wanting (this is mentioned in text-books as being a usua concomitant condition) and on neither hand is there a thumb. The ulnze are unusually stout as if to compensate for the first-mentioned deficiency. At birth and for some days afterwards the thenar border of the hand lay alongside the inner border of its ulna, the fingers pointing towards the elbow; this position is now modified, the hands being at right angles with the forearm. Using a little force the land can be brought to the extremity of the ulna and in the sam straight line, but the original position is assumed inme. diately on releasing. The child is for the rest beautivally shaped and there is nothing in the parental history which would lead one to anticipate such a misfortane.

Operton, Ellesmere.

\section{NOTES ON TWO TYPICAL EXAUPLES OF VARIETIES} OF OVARIAN TUMOUR.

BY JAMES OLIVER, M.D., F.R.S. EDIN., PHYSICLAN TO THE HOSPITAL FOR WONEN, SOHO-SQUARH:

CASE 1. Cholesteatoma; operation; recorery. A singlo woman, aged twenty-five years, began to menstruate at the age of sixteen years. Since its appearance the menstrual discharge had reappeared regularly; it had always been scanty and accompanied by pain, seldom severe, in the lower abdomen. Two years ago the patient had datected a small lump in the hypogastric region. For twenty-one months it geemed to have maintained the same size and as it produced practically no discomfort she paid little heed to its existence. Three months ago she was seized suddenly with severe pain in the lower abdomen and as the pain had continued more or lese since its onset and the lump had steadily increased in size 